\title{
Hearing Toxicity Induced by Tripterygium Glycosides in Zebrafish
}

\author{
Huifang Xu ${ }^{1, \dagger}$, Xuxia Tang ${ }^{1, \dagger}$, Jingjing $\mathrm{Chen}^{1}$, Ya Shi ${ }^{1}$, Jun Liu ${ }^{1}$, Shengya Guo ${ }^{2}$, Jiali Zhou ${ }^{2}$, \\ Chunqi $\mathrm{Li}^{2}$, Jing He Zhou ${ }^{3, *}$ \\ ${ }^{1}$ Otolaryngology Department, Zhejiang Provincial Hospital of Traditional Chinese Medical, Hangzhou, China \\ ${ }^{2}$ Hunter Biotechnology, Hangzhou, China \\ ${ }^{3}$ Department of Plastic Surgery, Affiliated Hangzhou First People's Hospital Zhejiang University School of Medicine, Hangzhou, China
}

Email address:

xuhuifang0313@outlook.com (Huifang Xu),112714216@qq.com (Xuxia Tang),3130323313@qq.com (Jingjing Chen),

Shiya920@126.com (Ya Shi), liujunmn18@sina.com (Jun Liu), guosy1988@163.com (Shengya Guo),

819537524@qq.com (Jiali Zhou), fisher200@163.com (Chunqi Li), zhoujinghe0311@126.com (Jing He Zhou)

${ }^{*}$ Corresponding author

$\dagger$ Huifang Xu and Xuxia Tang are co-first authors.

\section{To cite this article:}

Huifang Xu, Xuxia Tang, Jingjing Chen, Ya Shi, Jun Liu, Shengya Guo, Jiali Zhou, Chunqi Li, Jing He Zhou. Hearing Toxicity Induced by Tripterygium Glycosides in Zebrafish. International Journal of Animal Science and Technology. Vol. 5, No. 3, 2021, pp. 79-86. doi: $10.11648 /$ j.jjast.20210503.15

Received: September 2, 2021; Accepted: September 22, 2021; Published: September 30, 2021

\begin{abstract}
Tripterygium glycosides (TG) is isolated from an extensively used traditional Chinese medicine herb tripterygium roots and has been extensively used in the treatment of rheumatoid arthritis, nephrotic syndrome, hyperthyroidism and other diseases due to its anti-inflammatory and immunosuppressive effects. Hearing toxicity has been recently associated with $T G$ use in human patients. In this study, authors assessed hearing toxicity and possible molecular toxic mechanisms of $T G$ in a whole animal model. The maximum non-lethal concentration (MNLC) of $T G$ on the zebrafish was $21 \mathrm{mg} / \mathrm{L}$. $T G$ induced zebrafish hair cell loss in a dose-dependent manner $(\mathrm{p}<0.001)$, and the saccular otolith size reduction when treated at MNLC $(\mathrm{p}<0.01) . T G$ treatment resulted in sound-stimulated zebrafish movement reduction $(\mathrm{p}<0.001)$; and the rollover zebrafish percentages were elevated as $T G$ treatment concentrations moved up. Following $T G$ treatment, mRNA levels of the zebrafish hearing organ development genes eyal and val were remarkably downregulated, and the expression of apoptosis-associated genes bax and caspase 3 was significantly enhanced $(\mathrm{p}<0.05)$. These findings confirm the hearing toxicity of $T G$ and suggest its toxic mechanisms probably are through suppressing hearing cell development and promoting hearing cell apoptosis. Authors recommend zebrafish assay as a quick and reliable screening test of hearing toxicity for drugs and health products.
\end{abstract}

Keywords: Tripterygium glycosides, Hearing Toxicity, Hair Cell, Zebrafish

\section{Introduction}

Hearing loss is one of the major health problems worldwide [1]. A variety of marketed drugs such as streptomycin, gentamycin and cisplatinum are known to cause hearing toxicity in humans $[2,3]$. The principal symptoms of hearing toxicity include the reduced hearing, tinnitus and disequilibrium. Recently, hearing toxicity induced by Chinese medicines, plants-derived drugs and health products has been paid attention [4]. However, the Food and Drug Administration (FDA) does not require hearing toxicity screening in either the preclinical or clinical testing stages of drug development, and there are no Good Clinical Practice (GCP) guidelines in place for hearing toxicity identification [5]. Similarly, ICH guidelines call for a core battery of nonclinical safety pharmacology studies for human pharmaceuticals, but do not include auditory testing [6]. The absence of standard testing protocols to identify ototoxic effects at the pre-clinical stage is a major reason for the incidence of these adverse effects in the clinic [7].

Tripterygium roots is a well-known and patented traditional Chinese medicine and also uses in East Asia and part of 
America. Its extract tripterygium glycosides (TG) are widely used to treat a variety of clinical autoimmune and inflammatory diseases such as rheumatoid arthritis [8-11] and chronic glomerulonephritis [12-14]. Despite the potential therapeutic benefits, multiple adverse reactions, including digestive tract problems, kidney dysfunction, reproductive system and blood circulatory systems disturbances and hematotoxicity, have been reported in $T G$-taking patients [9, $15,16]$. Not long ago, a Chinese pharmaceutical journal summarized the clinical side effects of tripterygium roots and surprisingly found that the hearing reduction could have been associated with the use of this medicine herb or its extracts [17], but this postulation has never been experimentally confirmed and elucidated.

The zebrafish have a pair of typical vertebrate inner ears with both hearing organs and vestibular organs [18] and have been recognized as an excellent model system to study developmental processes relating to hearing and deafness [19]. Zebrafish have lateral line organs, consisting of sensory hair cells, mantle cells and supporting cells called neuromasts, which are structurally and functionally similar to human inner ear hair cells [20-22]. The otoliths are biomineralized ear stones that contribute to both hearing and vestibular function in fish. Zebrafish otoliths consist of a proteinaceous matrix biomineralized by the crystalline growth of aragonitic calcium carbonate and several glycoprotein components of zebrafish otoliths have been identified [3]. The genes involved in hearing functions and in apoptosis pathways are highly conserved between the zebrafish and mammals, making zebrafish a predictable animal model to identify ototoxic compounds and facilitating drug screening and investigations of the mechanisms associated with the hearing damage [3, 24].

In this study, authors found that $T G$ induced hair cell loss and reduced saccular otolith area in zebrafish in a dose-dependent manner, and correspondingly, sound-stimulated movement was declined in $T G$-treated zebrafish. Moreover, the hearing organ developmental genes eyal and val were significantly downregulated, whereas apoptosis-associated genes bax and caspase3 were upregulated, in the zebrafish exposed to $T G$ treatment.

\section{Materials and Methods}

\subsection{Zebrafish Breeding and Culture}

Adult AB strain zebrafish were housed in an AAALAC (the Association for Assessment and Accreditation of Laboratory Animal Care) International, CNAS (the China National Accreditation Service for Conformity Assessment), and CMA (the China Inspection Body and Laboratory Mandatory Approval) accredited zebrafish laboratory [25] and fed with live brine shrimp twice daily and dry flake once a day. Zebrafish were set up for nature mating and embryos were maintained at $28^{\circ} \mathrm{C}$ in fish water consisting of $0.02 \%$ Instant Ocean Salt in deionized water, $\mathrm{pH} 6.9 \sim 7.2$, conductivity 480 $\sim 510 \mathrm{mS} / \mathrm{cm}$ and hardness $53.7 \sim 71.6 \mathrm{mg} / \mathrm{L} \mathrm{CaCO}_{3}$. The zebrafish embryos were washed and staged at 6 and $24 \mathrm{hpf}$ (hours post fertilization) under a dissecting stereomicroscope. The animal care and use for this study was approved by the Institutional Animal Care and Use Committee (IACUC) of Hunter Biotechnology, Inc.

\subsection{Chemicals and Reagents}

Tripterygium glycosides tablets were acquired from the Zhejiang De ende Pharmaceutical Co., Ltd (Zhejiang, China). 2-(4-(dimethylamino)styryl) -N-ethylpyridinium iodide (DASPEI) was purchased from Sigma-Aldrich (St. Louis, MO, USA). Trizol reagent were from Invitrogen Life Technologies (USA), reverse transcriptase kit from TIANGEN Biotech (Beijing, China), and the SYBR Green system from Biorad (USA).

\subsection{TG-induced Zebrafish Lethality Analysis}

$T G$ was dissolved in dimethyl sulfoxide (DMSO, Sigma, St. Louis, USA) and stock solutions were prepared in fish water with a final DMSO concentration of $0.1 \%(\mathrm{v} / \mathrm{v})$, Fifteen zebrafish per group were exposed to $T G$ for $24 \mathrm{~h}$ from $5 \mathrm{dpf}$ to $6 \mathrm{dpf}$, and mortality and toxicity were recorded at the end of treatment. In the initial tests, 5 testing concentrations at 5, 10, 25, 50 and $100 \mathrm{mg} / \mathrm{L}$ were used. Dead zebrafish was defined as the absence of heartbeat under a dissecting stereomicroscope. Total number of dead zebrafish were applied to generate a lethality curve by plotting lethality (\%) vs concentration. Based on the lethality curve, the maximum non-lethal concentration (MNLC) was estimated with the GraphPad Prism 5.0 software (GraphPad, Inc., San Diego, CA, USA).

\subsection{TG Treatment for Hearing Toxicity Assay}

The zebrafish at $5 \mathrm{dpf}$ were treated for $24 \mathrm{~h}$ with $T G$ in $3 \mathrm{~mL}$ of fish water per well in a 6-well plate (Nest Biotech., Shanghai, China). Based on the lethality curve, 4 concentrations of $T G$ maximum up to the MNLC $(2.63 \mathrm{mg} / \mathrm{L}$, $5.25 \mathrm{mg} / \mathrm{L}, 10.5 \mathrm{mg} / \mathrm{L}$, and $21 \mathrm{mg} / \mathrm{L}$ ) were selected and tested. Zebrafish treated with fish water served as an untreated control. 2-(4-(dimethylamino)styryl)-N-ethylpyridinium iodide (DASPEI; Molecular Probes, Eugene, OR, USA), a hair cells-specific fluorescent vital dyes [26], was used to label the lateral neuromasts in zebrafish [24]. After treatment, zebrafish at $6 \mathrm{dpf}$ were washed with fish water for 3 times and immersed in $1 \mathrm{mM}$ DASPEI dissolved in fish water for $1 \mathrm{~h}$. After thoroughly washing, zebrafish were anaesthetized with MESAB (0.5 mM 3-amino-benzoic acid ethyl ester, $2 \mathrm{mM}$ $\mathrm{Na}_{2} \mathrm{HPO}_{4}$ ) and 10 zebrafish from each group were randomly selected for imaging under a stereo fluorescence microscope (AZ100, Nikon, Japan). Image J software (NIH, USA) was used to quantify the staining intensity (S) of hair cells in the zebrafish lateral line neuromasts, and hearing toxicity was calculated using the following formula: hair cells loss $(\%)=(1-$ $\left.\left[\mathrm{S}_{T G} / \mathrm{S}_{\text {Control }}\right]\right) \times 100 \%$.

\subsection{Assessing Toxicity on the Zebrafish Statocyst}

After $T G$ treatment, 10 zebrafish from each group were selected and images were taken under a dissecting microscope 
(Olympus SZX7, Japan). Nikon NIS-Elements D 3.10 Advanced image processing software was used to capture and analyze the images. The saccular otolith area (A) was measured and quantified. The reduction of otolith area (\%) in zebrafish treated with $T G$ was calculated based on the following formula: reduction of statocyst $(\%)=(1-$ $\left.\left[\mathrm{A}_{T G} / \mathrm{A}_{\text {Control }}\right]\right) \times 100 \%$.

\subsection{Sound-stimulated Zebrafish Movement Quantification}

At the end of treatment, the rollover zebrafish numbers were counted for each group under a dissecting microscope. Meanwhile, sound-stimulated larval locomotor activity was quantified with a Video-Track system and its supplied software (Video-Track software, ViewPoint Life Science, France). A frequency of $440 \mathrm{~Hz}$ was used as a universal startle-stimulus [27]. Living zebrafish with no deformity were selected and plated into a 96-well plate with a single zebrafish in each well. Before monitoring, the larval zebrafish were acclimated in the 96 -wells at $28^{\circ} \mathrm{C}$ for $10 \mathrm{~min}$. The total distance moved (D) by continuous visible dark transition was measured and the movement reduction (\%) in zebrafish treated with $T G$ was calculated following the formula below: reduction of total distance $(\%)=\left(1-\left[\mathrm{D}_{T G} / \mathrm{D}_{\text {Control }}\right]\right) \times 100 \%$.

\subsection{Gene Expression Analysis}

The hearing organ developmental genes eyal (eyes absent gene) and val (valentino gene) and apoptosis-associated genes bax and caspase 3 were determined by Q-PCR, and the primer sequences were designed following a published paper as indicated in Table 1 [28]. As described in previous reports [25], zebrafish RNA was extracted using Trizol reagent (Invitrogen Life Technologies) and transcribed to cDNA with the FastQuant RT Kit (With gDNase) (Tiangen). Q-PCR was performed with a CFX Connect detection system (Biorad) using the iTaq Universal SYBR Green Supermix (Biorad), in which there were three technical or biological replicates: $95^{\circ} \mathrm{C}$ for $2 \mathrm{~min}$, followed by 40 cycles of 5 seconds $95^{\circ} \mathrm{C}$, and 30 seconds at $60^{\circ} \mathrm{C}$. Gene expression was normalized against the expression of $\beta$-actin [29].

Table 1. Primer sequences used in the real-time quantitative PCR

\begin{tabular}{lll}
\hline Gene & Forward (5'-3') & Reverse (5'-3') \\
\hline$\beta$-actin & TCGAGCAGGAGATGGGAACC & CTCGTGGATACCGCAAGATTC \\
Caspase3 & CCGCTGCCCATCACTA & TCCGATCTGCTGCAAACACT \\
Bax & GACTTGGGAGCTGCACTTCT & AGTCAGGAGGTGGAGACG \\
Val & CCGTGTCCTCCACTCCTA & GCTGCGTCTTCTCGTTCT \\
Eyal & CTTCAGCCCAAGACAAAC & AGTCAGGAGGTGGAGACG \\
\hline
\end{tabular}

\subsection{Statistical Analysis and Quality Control}

One-way ANOVA followed by the Dunnett's test was used to compare differences among groups. All statistical analyses and figures were generated with GraphPad Prism 5.0 Software (GraphPad, Inc., San Diego, CA, USA), and $\mathrm{p}<0.05$ was considered statistically significant. All quantitative data were expressed as mean \pm standard error (SE), and results were statistically compared between sample-treated and control zebrafish groups. Successful experiments must meet all the quality control milestones below: (i) zebrafish natural death in untreated and vehicle-treated groups was $\leq 10 \%$; (ii) intraplate and interplate CV (coefficient of variation) was $\leq 25 \%$ [30].

\section{Results}

\subsection{TG-induced Zebrafish Death}

MNLCs were determined using a procedure as described in materials and methods. $T G$-induced death was observed in a dose-dependent manner, and no survival could be seen with $T G$ above $50 \mathrm{mg} / \mathrm{L}$ and no death occurred with $T G$ below 10 $\mathrm{mg} / \mathrm{L}$. The best-fit concentration response curves were generated and provided in Figure 1 and MNLC was calculated from these curves. The MNLC was $21 \mathrm{mg} / \mathrm{L}$ for $T G$, and therefore, 4 concentrations at $2.63,5.25,10.5$, and $21 \mathrm{mg} / \mathrm{L}$ were selected for the hearing toxicity tests.

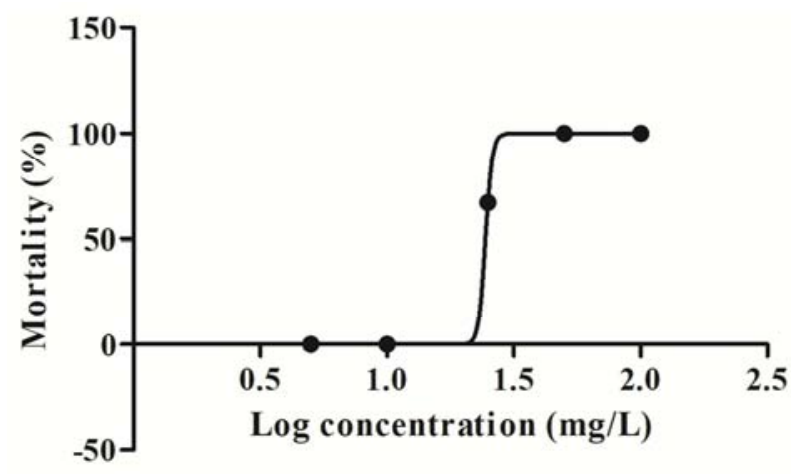

Figure 1. The concentration-death curve of zebrafish treated with TG.

\subsection{TG-induced Zebrafish Hair Cell Loss}

DASPEI stained zebrafish neuromast hair cells specifically (Figure 2A). As indicated in Figure 2B, neuromasts were shown as black dots derived from the inverted fluorescent images. In the pilot studies, authors found that solvent solution of $0.1 \%$ DMSO did not induce hair cell damage, demonstrating this solvent had no adverse effect on the zebrafish neuroblasts (data not shown). The zebrafish lateral line neuromasts were damaged and significantly lost after treatment with $T G$ in a dose-dependent manner. Almost complete loss of hair cells in lateral line neuromasts were found when the zebrafish were treated with $21 \mathrm{mg} / \mathrm{L}$ of $T G$. In zebrafish treated groups with $T G$ at concentration of 2.63 $\mathrm{mg} / \mathrm{L}, 5.25 \mathrm{mg} / \mathrm{L}, 10.5 \mathrm{mg} / \mathrm{L}$ and $21 \mathrm{mg} / \mathrm{L}$, the fluorescence 
intensity was $117796,114892,8504$ and 1620, respectively, (Figure 2C), and the percentage of hair cells loss was $6.3 \%$, $7.7 \%, 45.6 \%$ and $95.0 \%$, respectively (Figure 2D). A student's t-test confirmed that these decreases in hair cells at 10.5 and $21 \mathrm{mg} / \mathrm{L}$ were statistically significant $(\mathrm{p}<0.001)$ as compared with the untreated control group.

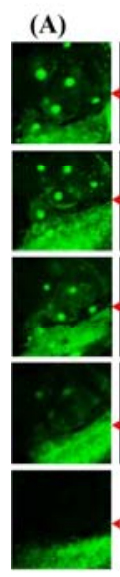

(C)

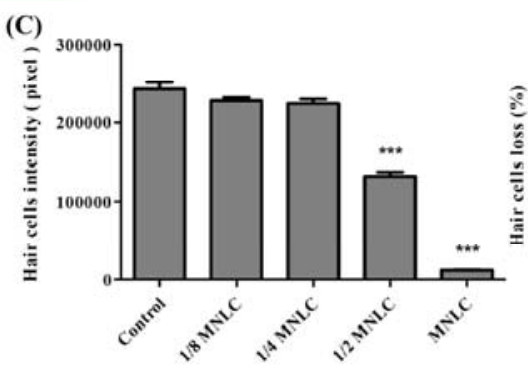

(B)

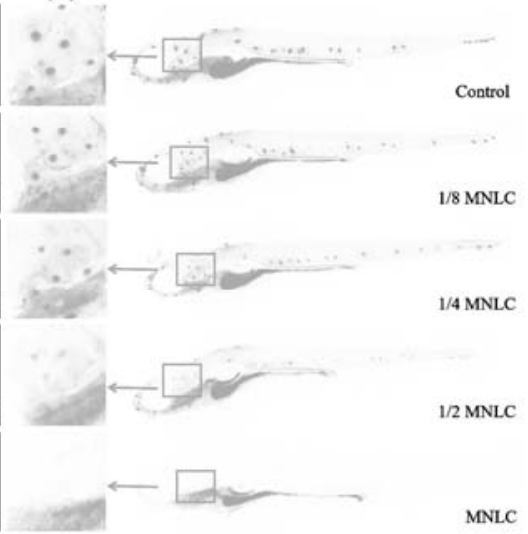

(D)

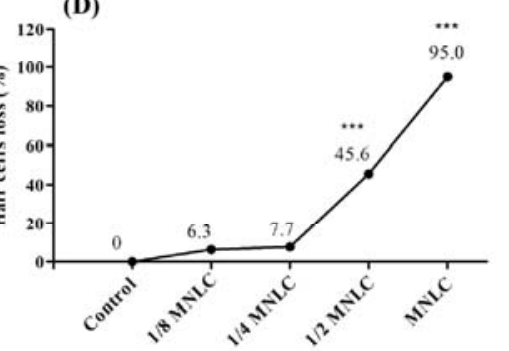

Figure 2. Visual assessment of hearing toxicity in zebrafish treated with TG. (A) The neuromasts of the lateral line were labeled with DASPEI; (B) Fluorescent DASPEI images were inverted for particle analysis, Neuromasts stereotypically located on the body were stained as black dots; (C) The fluorescence intensity of hair cells was quantified in lateral line neuromasts, Hair cells in lateral line neuromasts were decreased in TG-treated zebrafish; (D) Hair cells loss in TG-exposed zebrafish. Data were expressed as mean $\pm S E$. Compared with control group, ***p<0.001. 1/8 MNLC=2.63 mg/L, 1/4 MNLC=5.25 mg/L, $M N L C=10.5 \mathrm{mg} / L, M N L C=21 \mathrm{mg} / L$.

\subsection{TG-induced Zebrafish Statocyst Damage}

$T G$-treated zebrafish displayed abnormal otic capsules including small sacculus (Figure 3A) and the reduced the saccular otoliths area at the highest tested concentration of $21 \mathrm{mg} / \mathrm{L}$ (Figure 3B), and the saccular otoliths were $11.5 \%$ smaller than untreated control zebrafish $(\mathrm{p}<0.01$, Figure $3 \mathrm{C})$.

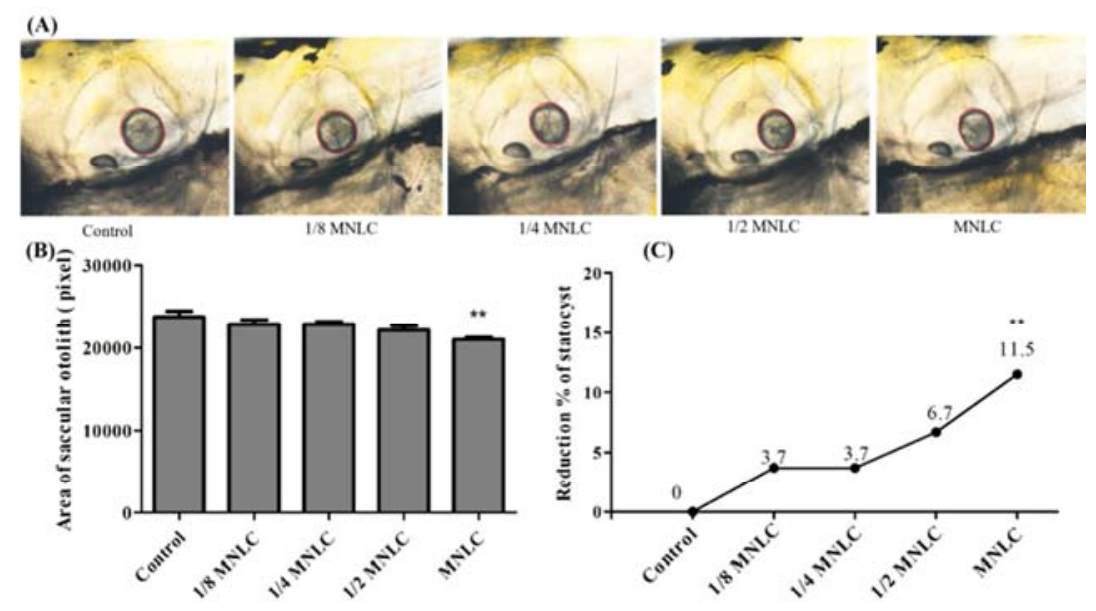

Figure 3. The zebrafish ears. (A) Bright field images of the ear of a wild type zebrafish at 6 dpf. The otoliths and semicircular canals were observed. Otolith change in zebrafish larvae exposed to TG; (B) The area of saccular otolith was quantified in zebrafish inner ear; (C) The reduction of statocyst (saccular otolith area) (\%) in TG-exposed zebrafish. Data were expressed as mean $\pm S E$. Compared with control group, **p<0.01. $1 / 8 \mathrm{MNLC}=2.63 \mathrm{mg} / \mathrm{L}, 1 / 4 \mathrm{MNLC}=5.25 \mathrm{mg} / \mathrm{L}$, $M N L C=10.5 \mathrm{mg} / L, M N L C=21 \mathrm{mg} / \mathrm{L}$. 


\subsection{TG-induced Sound-stimulated Zebrafish Motility Disorders}

Zebrafish hair cell damage after the $T G$ exposure exhibited an aberrant swimming behavior: rollover and the reduced motility in response to sound stimulation. There were no rollover zebrafish in normal control group and in the groups of zebrafish treated with $2.63 \mathrm{mg} / \mathrm{L}, 5.25 \mathrm{mg} / \mathrm{L}$ and $10.5 \mathrm{mg} / \mathrm{L}$ of $T G$. The rollover percentage was $20 \%$ in zebrafish treated with $T G$ at the highest tested concentration of $21 \mathrm{mg} / \mathrm{L}$. Zebrafish locomotion activities under a sound stimulation after $T G$ treatment were measured as displayed in Figure 4A. Zebrafish movement distance decreased significantly after $T G$ treatment (Figure 4B). The reduction percentage of total distance was $-2.8 \%$, $9.2 \%, 9.9 \%$ and $42.4 \%$, respectively, after zebrafish exposed to $T G$ at concentrations of $2.63 \mathrm{mg} / \mathrm{L}, 5.25 \mathrm{mg} / \mathrm{L}$, $10.5 \mathrm{mg} / \mathrm{L}$ and $21 \mathrm{mg} / \mathrm{L}$, respectively, and statistically significant difference was observed when treated at 21 $\mathrm{mg} / \mathrm{L}$ as compared with the control group (Figure 4C) $(\mathrm{p}<0.001)$.

(A) Control
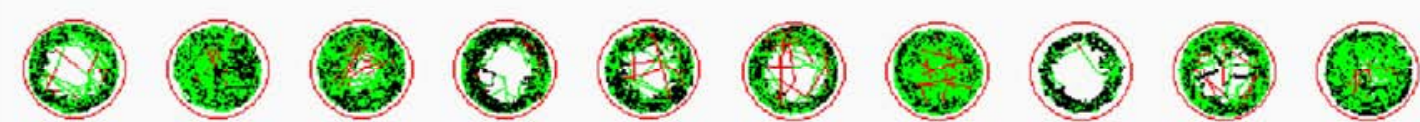

$1 / 8 \mathrm{MNLC}$
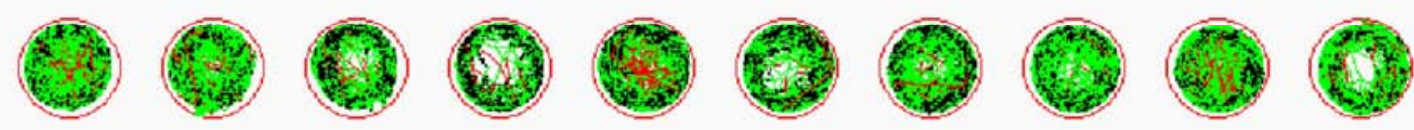

$1 / 4 \mathrm{MNLC}$
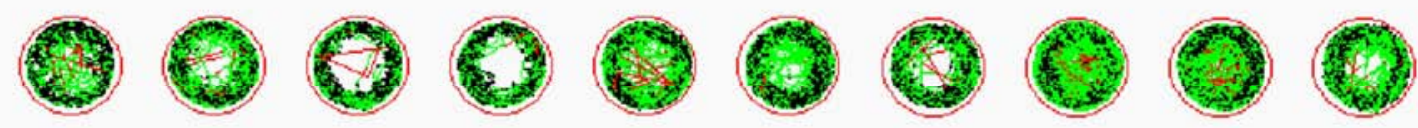

$1 / 2 \mathrm{MNLC}$
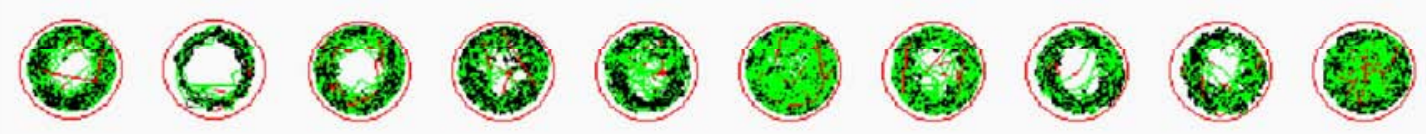

MNLC
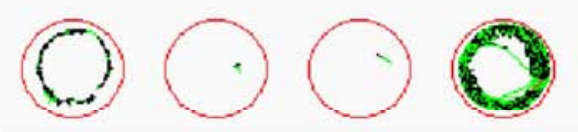

(B)
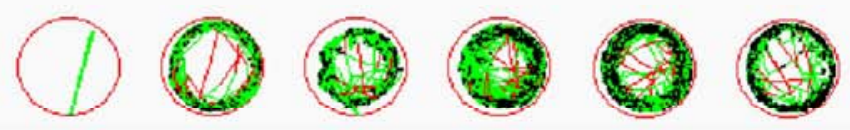

(C)
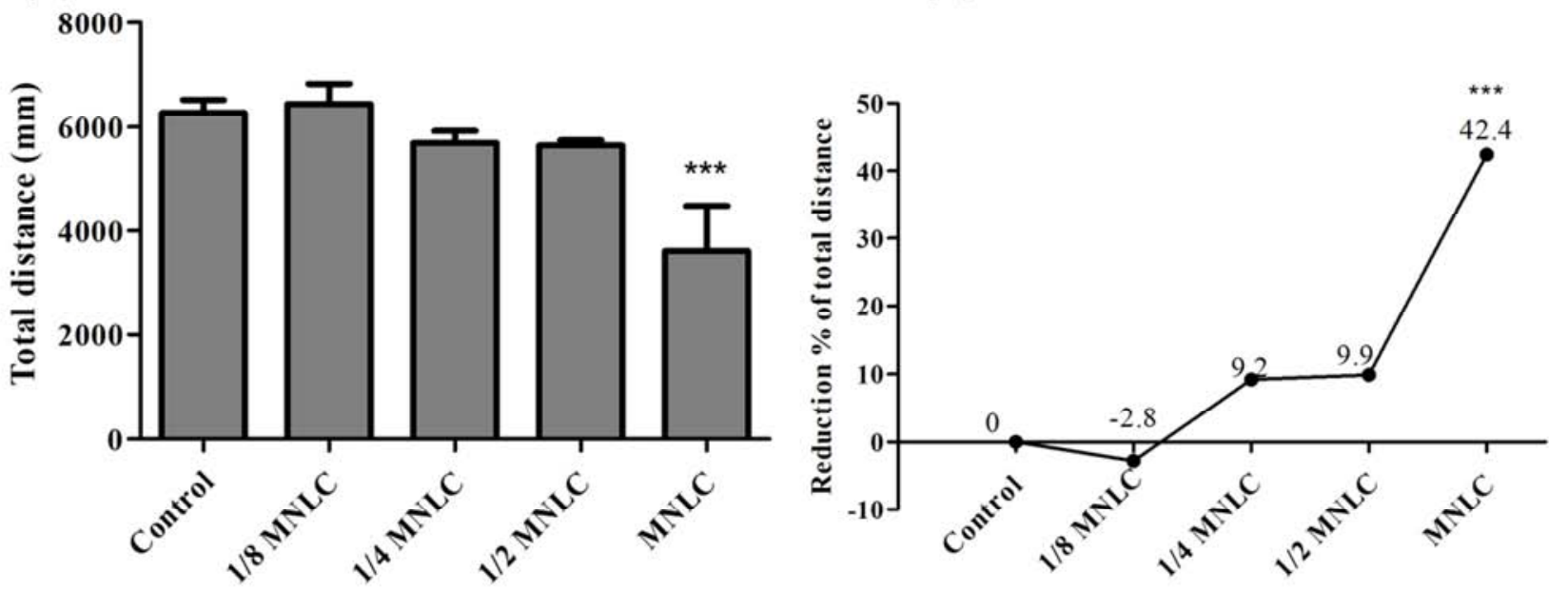

Figure 4. Zebrafish movement assay. (A) Swimming tracks of zebrafish with TG-induced abnormal swimming behavior; (B) The total distance was quantified in zebrafish; (C) The reduction\% of total distance in TG-treated zebrafish. Data were expressed as mean $\pm S E$. Compared with control group, ** $<0.01$. $1 / 8$ $M N L C=2.63 \mathrm{mg} / \mathrm{L}, 1 / 4 \mathrm{MNLC}=5.25 \mathrm{mg} / \mathrm{L}, M N L C=10.5 \mathrm{mg} / \mathrm{L}, M N L C=21 \mathrm{mg} / \mathrm{L}$.

\subsection{Molecular Mechanisms of TG-induced Hearing Toxicity}

The mRNA levels of gene expression related to the hearing organ development and apoptosis in zebrafish were quantified after $T G$ exposure at 6 dpf. The results demonstrated that the genes eyal and val transcriptions were significantly downregulated by $0.73-$ and 0.60 - folds in the

group of zebrafish treated with $T G$ at $21 \mathrm{mg} / \mathrm{L}(\mathrm{p}<0.01)$. Conversely, the gene bax was upregulated for 1.49- and 2.55 -folds at 10.5 and $21 \mathrm{mg} / \mathrm{L}$ of treatment groups $(\mathrm{p}<0.001)$; and the gene caspase 3 was upregulated by $1.23,1.21$ and 1.18 -folds at $5.25,10.5$ and $21 \mathrm{mg} / \mathrm{L}$ of treatment groups $(\mathrm{p}<0.01)$, respectively (Figure 5$)$. 


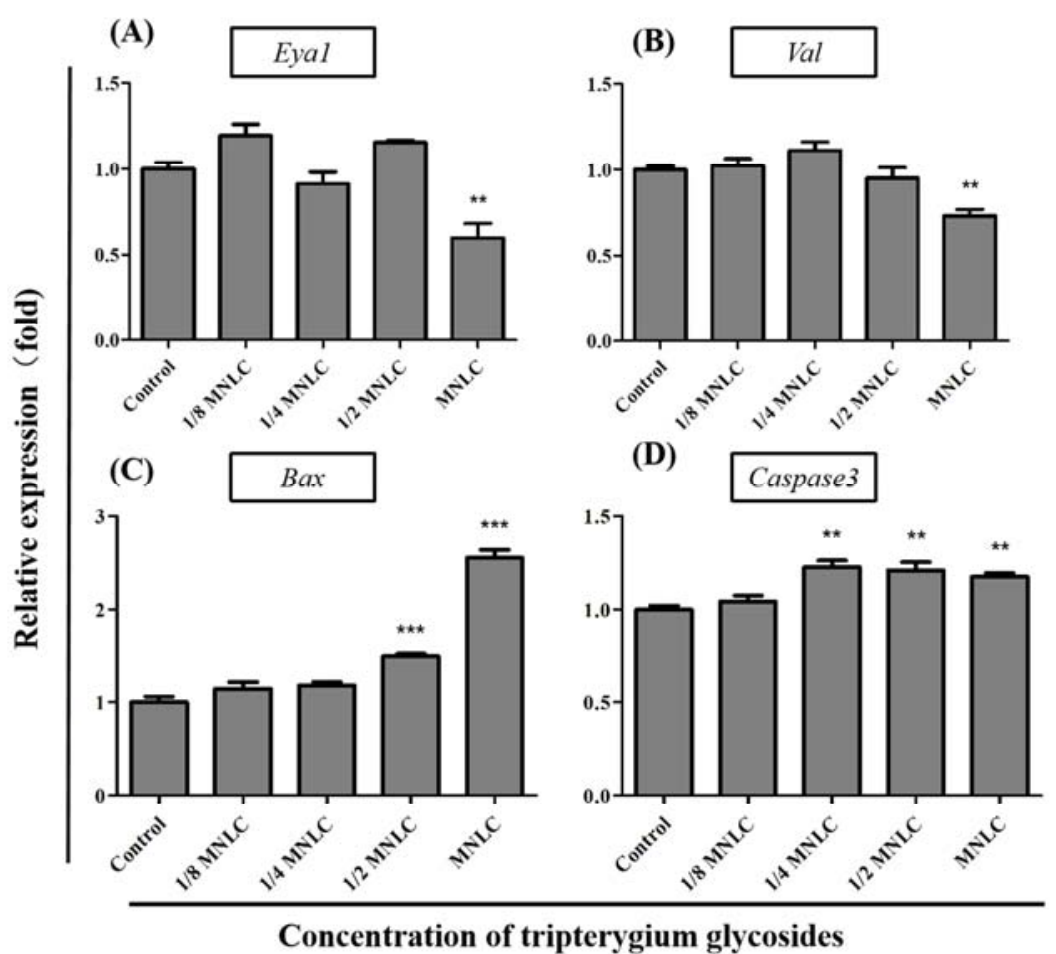

Figure 5. Expression levels of hearing organ developmental genes and apoptosis genes in the zebrafish treated with a variety of concentrations of TG at 6 dpf. Eyal (A) and val (B) genes were markedly down-regulated; and Bax (C) and caspase3 (D) genes were significantly up-regulated after TG treatment. Data were expressed as mean $\pm S E$. Compared with the control group, ${ }^{* *} p<0.01 ; * * * p<0.001 .1 / 8 M N L C=2.63 \mathrm{mg} / L, 1 / 4 \mathrm{MNLC}=5.25 \mathrm{mg} / \mathrm{L}, \mathrm{MNLC}=10.5 \mathrm{mg} / \mathrm{L}$, $M N L C=21 \mathrm{mg} / \mathrm{L}$.

\section{Discussion}

In this study, using zebrafish as a model organism, authors found that a clinically plant-derived medicine $T G$ induced hair cell loss, and saccular otolith area and sound-stimulated movement reduction, confirming that $T G$ is an ototoxic drug. Authors also discovered that $T G$ treatment resulted in reduced expression of the hearing organ developmental genes eyal and val but elevated apoptosis genes bax and caspase 3 levels, implying that $T G$ induced hearing toxicity and hearing toxicity-associated movement dysfunctions in zebrafish probably through suppressing hearing developmental gene expression and inducing apoptosis.

$T G$-induced common toxicity such as hepatic damage and reproductive toxicity has been extensively reported and characterized, but its possible toxicity to the hearings has just been recently suspected [17]. Zebrafish are an inexpensive and rapid alternative to rodents for evaluating chemical and drug toxicity [31,32], and previous studies have confirmed that zebrafish are a highly predictive animal model for in vivo screening of hearing toxicity [7].

In larval zebrafish, hair cells are present both within the inner ear and the lateral-line system [19, 33-37]. Numerous studies have demonstrated that human toxins can destroy or damage hair cells in the lateral line of larval zebrafish $[4,38]$. In the present study, authors used zebrafish to visualize the inner ear toxicity induced by $T G$. Hair cell survival was assessed by the relative fluorescent intensity of staining with the mitochondrial potential dye DASPEI. As demonstrated by the results, within $24 \mathrm{~h}$ of treatment, $T G$ at $1 / 2 \mathrm{MNLC}$ and above concentrations could induce markedly hair cells loss. The saccular otolith areas in $T G$-treated zebrafish were significantly smaller than untreated control zebrafish, indicating the auditory was damaged. In addition, in all of the experiments, no death of zebrafish was found in untreated groups and no statistical differences in assessed endpoints were found among the control groups.

The reduced otoliths in the zebrafish treated with $T G$ in this study further support that $T G$ is toxic to hearing. Zebrafish are so-called "hearing specialists" using a combination of their acoustico-lateralis system, swim bladder and Weberian ossicles to detect sound [39]. The inner ear of zebrafish consists mainly of three semicircular canals and two statocyst called utricle (utricular or anterior macula) and saccule (saccular or posterior macula), each with an overlying otolith [40]. Otoliths transmit acceleration forces and sound vibrations to the ciliary bundles of macular hair cells, thereby contributing to the vestibular function of the animal.

Hair cell death is the leading cause of hearing and balance disorders in humans. It can be triggered by multiple insults, including genetic mutations, noise, trauma, aging and treatment with certain therapeutic drugs [41-45]. Behavioral and morphological effects have also been produced by sound deprivation during a critical period in the development of the auditory system [46]. Consistently, in this study, aberrant swimming behavior, such as the zebrafish rollover and dysfunctional locomotion activity, were observed in the 
zebrafish following $T G$ treatment at concentrations $21 \mathrm{mg} / \mathrm{L}$, implying a dose-associated hearing toxicity of $T G$.

Eya regulates organogenesis in both vertebrates and invertebrates. The zebrafish eyal gene is expressed during embryogenesis in multiple types of cells [47] and the loss of eyal function in the zebrafish embryo leads to premature apoptosis and small otolith [28]. Apoptosis was also reported from loss of eya gene function in Drosophila and mouse [48, 49]. Val is involved in the early development of the zebrafish otic vesicles and it is an indispensable transcription factor in each process of otic vesicles development [50]. The decreased expression of eyal and val could damage hearing organs development after $T G$ treatment.

$\mathrm{Bax}$ is a pro-apoptotic $\mathrm{Bcl}-2$ family proteins which promote cell death [51], closely associated with caspase activation and classical apoptosis $[52,53]$. Caspase 3 is a primary downstream caspase that executes the apoptotic program by cleavage of proteins necessary for cell survival, including $B c l-2$, inhibitors of deoxyribonucleases, and cytoskeletal proteins [54-57]. TG treatment resulted in up-regulations of bax and caspase 3 genes, demonstrating that $T G$ treatment induces cell death including hearing organ cells in the zebrafish.

\section{Conclusion}

The results of authors zebrafish based study confirmed that $T G$ could cause hearing toxicity. $T G$ induced hair cell damage, saccular otolith atrophy and motility reduction, zebrafish rollover. Besides, the apoptosis related genes (bax and caspase3) were significantly upregulated and the hearing developmental genes (Eyal and $\mathrm{Val}$ ) were significantly downregulated after exposed to TG. These findings indicate that the potential risk of hearing toxicity of TG should be considered when it is administered to patients.

\section{Acknowledgements}

This work was supported by Project of Administration of Traditional Chinese Medicine of Zhejiang Province of China (No. 2018ZQ018).

\section{References}

[1] Arslan E, Orzan E, Santarelli R. Global problem of drug-induced hearing loss. Ann N Y Acad Sci 1999; 884 (1): $1-14$.

[2] Buck LM, Winter MJ, Redfern WS, Whitfield TT. Ototoxin-induced cellular damage in neuromasts disrupts lateral line function in larval zebrafish. Hearing Res 2012; 284 (1-2): 67-81.

[3] Chiu LL, Cunningham LL, Raible DW, Rubel EW, Ou HC. Using the zebrafish lateral line to screen for ototoxicity. J Assoc Res Otolaryngol 2008; 9 (2): 178-90.

[4] Rah YC, Yoo MH, Choi J, Park S, Park HC, Oh KH, et al. In vivo assessment of hair cell damage and developmental toxicity caused by gestational caffeine exposure using zebrafish (Danio rerio) models. Neurotoxicol Teratol. 2017; 64: 1-7.

[5] Anon. FDA Guidance for Industry: M3 (R2) nonclinical safety studies for the conduct of human clinical trials and marketing authorization of pharmaceuticals: US Department of Health and Human Services Food and Drug Administration CDER CBER 2010.

[6] ICH. ICH S7A: Safety pharmacology studies for human pharmaceuticals 2005.

[7] Ou H, Simon JA, Rubel EW, Raible DW. Screening for chemicals that affect hair cell death and survival in the zebrafish lateral line. Hearing Res 2012; 288 (1-2): 58-66.

[8] Bu X, Fan J, Hu X, Bi X, Peng B, Zhang D. Norwegian scabies in a patient treated with Tripterygium glycoside for rheumatoid arthritis. An Bras Dermatol 2017; 92 (4): 556-8.

[9] Canter PH, Lee HS, Ernst E. A systematic review of randomised clinical trials of Tripterygium wilfordii for rheumatoid arthritis. Phytomedicine 2006; 13 (5): 371-7.

[10] Tao X, Cush JJ, Garret M, Lipsky PE. A phase I study of ethyl acetate extract of the chinese antirheumatic herb Tripterygium wilfordii hook F in rheumatoid arthritis. J Rheumatol 2001; 28 (10): 2160-7.

[11] Patavino T, Brady DM. Natural medicine and nutritional therapy as an alternative treatment in systemic lupus erythematosus. Altern Med Rev 2001; 6 (5): 460-71.

[12] Duan H, Takaishi Y, Momota H, Ohmoto Y, Taki T, Tori M, et al. Immunosuppressive terpenoids from extracts of Tripterygium wilfordii. Tetrahedron 2001; 57 (40): 8413-24.

[13] Wan YG, Zhao Q, Sun W, Zhang HL, Li M, Wei QX, et al. Contrasting dose-effects of multi-glycoside of Tripterygium wilfordii HOOK. f. on glomerular inflammation and hepatic damage in two types of anti-Thy1.1 glomerulonephritis. J Pharmacol Sci 2012; 118 (4): 433-46.

[14] Zhu B, Wang Y, Jardine M, Jun M, Lv J-C, Cass A, et al. Tripterygium Preparations for the Treatment of CKD: A Systematic Review and Meta-analysis. Am J Kidney Dis. 2013; 62 (3): 515-30.

[15] Pyatt DW, Yang Y, Mehos B, Le A, Stillman W, Irons RD. Hematotoxicity of the chinese herbal medicine Tripterygium wilfordii hook $\mathrm{f}$ in CD34-positive human bone marrow cells. Mol Pharmacol 2000; 57 (3): 512-8.

[16] Wang J, Wang C, Wu J, Li Y, Hu X, Wen J, et al. Oral microemulsion based delivery system for reducing reproductive and kidney toxicity of Tripterygium glycosides. J Microencapsul 2019; 36 (6): 523-34.

[17] Yun, N R. and Gan, J. S. Clinical side effect summary of ripterygium roots and preparation formulations. Tianjin Pharmaceuticals 2012; 24, 18-23.

[18] Popper A N. Hair cell heterogeneity and ultrasonic hearing: Recent advances in understanding fish hearing. Philos Trans $\mathrm{R}$ Soc Lond B Biol Sci 2000; 355 (1401): 1277-1280.

[19] Whitfield TT, Riley BB, Chiang MY, Phillips B. Development of the zebrafish inner ear. Dev Dynam 2002; 223 (4): 427-58.

[20] Fay. Comparative Hearing: Fish and Amphibians. Springer Berlin 1999; 11 (19): 1549-53. 
[21] Haddon C, Lewis J. Early ear development in the embryo of the zebrafish, Danio rerio. J Comp Neurol 1996; 365 (1): 113-28.

[22] Owens KN, Cunningham DE, MacDonald G, Rubel EW, Raible DW, Pujol R. Ultrastructural analysis of aminoglycoside-induced hair cell death in the zebrafish lateral line reveals an early mitochondrial response. J Comp Neurol 2007; 502 (4): 522-43.

[23] Abbas L, Whitfield TT. The zebrafish inner ear. Fish Physiol Biochem 2010; 29 (10): 123-71.

[24] Ton C, Parng C. The use of zebrafish for assessing ototoxic and otoprotective agents. Hearing Res 2005; 208 (1-2): 79-88.

[25] Guo S Y, Zhang Y, Zhu X Y, et al. Developmental neurotoxicity and toxic mechanisms induced by olaquindox in zebrafish. J Appl Toxicol 2020, 41 (4): 549-560.

[26] Balak K J, Corwin J T, Jones J E. Regenerated hair cells can originate from supporting cell progeny: Evidence from phototoxicity and laser ablation experiments in the lateral line system. J Neurosci 1990, 10 (8): 2502-2512.

[27] Zeddies DG, Fay RR. Development of the acoustically evoked behavioral response in zebrafish to pure tones. J Exp Biol 2005; 208 (Pt 7): 1363-72.

[28] Zhao Z, Tong JW, Zhang JP, You XF, Hu CQ. Zebrafish model for the study on drug ototoxicity of aminoglycoside antibiotics. Acta Pharm Sin 2011; 46 (8): 928-35.

[29] Sharif F, Steenbergen PJ, Metz JR, Champagne DL. Long-lasting effects of dexamethasone on immune cells and wound healing in the zebrafish. Wound Repair Regen 2015; 23 (6): 855-65.

[30] Zhou J, Guo S Y, Zhang Y, et al. Human prokinetic drugs promote gastrointestinal motility in zebrafish. Neurogastroent Motil 2014, 26 (4): 589-595.

[31] Hill AJ, Teraoka H, Heideman W, Peterson RE. Zebrafish as a model vertebrate for investigating chemical toxicity. Toxicol Sci 2005; 86 (1): 6-19.

[32] McGrath P, Li CQ. Zebrafish: a predictive model for assessing drug-induced toxicity. Discov Today 2008; 13 (9-10): 394-401.

[33] Bever MM, Fekete DM. Atlas of the developing inner ear in zebrafish. Dev Dynam 2002; 223 (4): 536-43.

[34] Ghysen A, Dambly-Chaudière C. Development of the zebrafish lateral line. Current Opinion Neurobiol 2004; 14 (1): 67-73.

[35] Metcalfe W. Organisation and development of the zebrafish posterior lateral line [M]. New York: Springer-Verlag 1989: $147-159$.

[36] Metcalfe WK, Kimmel CB, Schabtach E. Anatomy of the posterior lateral line system in young larvae of the zebrafish. $\mathrm{J}$ Comp Neurol 1985; 233 (3): 377-89.

[37] Raible DW, Kruse GJ. Organization of the lateral line system in embryonic zebrafish. J Comp Neurol 2000; 421 (2): 189-98.

[38] Yoo M H, Rah Y C, Choi J, et al. Embryotoxicity and hair cell toxicity of silver nanoparticles in zebrafish embryos. Int $\mathrm{J}$ Pediatr Otorhinolaryngol 2016, 83: 168-174.

[39] Fay RR, Popper AN. Acoustic stimulation of the ear of the goldfish (Carassius auratus). J Exp Biol 1974; 61 (1): 243-60.
[40] Pisam M, Jammet C, Laurent D. First steps of otolith formation of the zebrafish: role of glycogen? Cell Tissue Res 2002; 310 (2): 163-8

[41] Furness DN. Molecular basis of hair cell loss. Cell Tissue Res 2015; 361 (1): 387-99.

[42] Lenz DR, Avraham KB. Hereditary hearing loss: from human mutation to mechanism. Hearing Res 2011; 281 (1-2): 3-10.

[43] Nelson EG, Hinojosa R. Presbycusis: a human temporal bone study of individuals with downward sloping audiometric patterns of hearing loss and review of the literature. Laryngoscope 2006; 116: 1-12.

[44] Rybak LP, Whitworth CA. Ototoxicity: therapeutic opportunities. Drug Discov Today 2005; 10 (19): 1313-21.

[45] Schacht J, Talaska AE, Rybak LP. Cisplatin and aminoglycoside antibiotics: hearing loss and its prevention. Anat Rec 2012; 295 (11): 1837-50.

[46] Tees RC. Effects of early auditory restriction in the rat on adult pattern discrimination. J Comp Physiol Psychol 1967; 63 (3): 389-93

[47] Kozlowski DJ, Whitfield TT, Hukriede NA, Lam WK, Weinberg ES. The zebrafish dog-eared mutation disrupts eyal, a gene required for cell survival and differentiation in the inner ear and lateral line. Dev Biol 2005; 277 (1): 27-41.

[48] Bonini NM, Leiserson WM, Benzer S. The eyes absent gene: genetic control of cell survival and differentiation in the developing Drosophila eye. Cell 1993; 72 (3): 379-95.

[49] Xu PX, Adams J, Peters H, Brown MC, Maas R. Eya1-deficient mice lack ears and kidneys and show abnormal apoptosis of organ primordia. Nat Genet 1999; 23 (1): 113-7.

[50] Kwak SJ, Phillips BT, Heck R, Riley BB. An expanded domain of fgf3 expression in the hindbrain of zebrafish valentino mutants results in mis-patterning of the otic vesicle. Development 2002; 129 (22): 5279-87.

[51] Borner C. The Bcl-2 protein family: sensors and checkpoints for life-or-death decisions. Mol Immunol 2003; 39 (11): 615-47.

[52] Tait SW, Green DR. Mitochondria and cell death: outer membrane permeabilization and beyond. Nat Rev Mol Cell Bio 2010; 11 (9): 621-32.

[53] Van Delft MF, Huang DC. How the Bcl-2 family of proteins interact to regulate apoptosis. Cell Res 2006; 16 (2): 203-13.

[54] Cheng EH, Kirsch DG, Clem RJ, Ravi R, Kastan MB, Bedi A, et al. Conversion of Bcl-2 to a Bax-like death effector by caspases. Science 1997; 278 (5345): 1966-8.

[55] Kirsch DG, Doseff A, Chau BN, Lim DS, de Souza-Pinto NC, Hansford R, et al. Caspase-3-dependent cleavage of Bcl-2 promotes release of cytochrome c. J Biol Chem 1999; 274 (30): 21155-61.

[56] Kothakota S, Azuma T, Reinhard C, Klippel A, Tang J, Chu K, et al. Caspase-3-generated fragment of gelsolin: effector of morphological change in apoptosis. Science 1997; 278 (5336): 294-8.

[57] Lazebnik Y A, Kaufmann S H, Desnoyers S, et al. Cleavage of poly(adp-ribose) polymerase by a proteinase with properties like ice. Nature 1994, 371 (6495): 346-347. 